\title{
Effects of an acute strawberry (Fragaria $\times$ ananassa) consumption on the plasma antioxidant status of healthy subjects
}

\author{
S. Romandini ${ }^{\mathrm{a}}$, L. Mazzoni ${ }^{\mathrm{a}}$, F. Giampieri ${ }^{\mathrm{a}}$, S. Tulipani ${ }^{\mathrm{b}, \mathrm{c}, \mathrm{d}}$, M. Gasparrini ${ }^{\mathrm{a}}$, T.Y. Forbes-Hernandez ${ }^{\mathrm{a}}$, \\ N. Locorotondo ${ }^{\mathrm{e}}$, M. D’Alessandro ${ }^{\mathrm{e}}$, B. Mezzetti ${ }^{\mathrm{f}}, \mathrm{S}$. Bompadre ${ }^{\mathrm{g}}$ and J.M. Alvarez-Suarez ${ }^{\mathrm{a}, *}$ \\ ${ }^{a}$ Dipartimento di Science Cliniche Specialistiche ed Odontostomatologiche (DISCO), Sez. Biochimica, Facoltá di \\ Medicina, Universitá Politecnica delle Marche, Ancona, Italy \\ ${ }^{\mathrm{b}}$ Biomarkers and Nutritional \& Food Metabolomics Research Group, Department of Nutrition and Food Science, \\ Faculty of Pharmacy, XaRTA, INSA, University of Barcelona, Barcelona, Spain \\ ${ }^{\mathrm{c}}$ INGENIO-CONSOLIDER Program, Fun-C-Food CSD2007-063, Ministry of Science and Innovation, Madrid, Spain \\ ${ }^{\mathrm{d}}$ Research Laboratory, IMABIS Foundation, Virgen de la Victoria Clinical Hospital, Malaga, Spain \\ ${ }^{\mathrm{e}}$ LOCOROTONDO LABS S.r.l., Palermo, Italy \\ ${ }^{\mathrm{f}}$ Dipartimento di Scienze Agrarie, Alimentari e Ambientali (D3A), Universitá Politecnica delle Marche, Ancona, \\ Italy \\ ${ }^{\mathrm{g}}$ Dipartimento Scienze Biomediche e Sanità Pubblica, Facoltà di Medicina, Università Politecnica delle Marche, \\ Ancona, Italy
}

Received 21 January 2013; accepted 30 July 2013

\begin{abstract}
.
BACKGROUND: Berries are raising increasing interest in the last years because of their nutritional quality and the several bioactive compounds with antioxidant properties that contain. Many studies reported significant increases in the plasma antioxidant capacity after long term and acute consumptions of antioxidant-rich foods.

OBJECTIVE: The aim of this work was to confirm the healthy effect of strawberry consumption, evaluating the impact of an acute strawberry intake for 15 days on the plasma oxidative status of healthy volunteers.

METHODS: To investigate the possible changes in the total antioxidant capacity of plasma, TEAC, FRAP, BAP and -SHp tests were performed; furthermore, the proteins' carbonyl residues test and the d-ROMs test were conducted to evaluate the protection provided by the strawberry consumption against radical damage.

RESULTS: Acute strawberry consumption improved the plasma TAC, increasing FRAP and BAP values, both immediately after the strawberry consumption and the washout period. Similarly, the strawberry intake decreased proteins' carbonyl residues and d-ROMs test values.

CONCLUSIONS: This study confirms the nutritional quality of Alba strawberry cultivar and demonstrates that the acute strawberry intake improves the plasma antioxidant capacity, and protects plasma proteins from the radical damage, also after the washout period.
\end{abstract}

Keywords: Strawberry, human acute consumption, plasma antioxidant capacity, plasma radical damage

${ }^{*}$ Corresponding author: Dr. José M. Alvarez-Suarez, PhD DISCO, Facoltà di Medicina, Università Politecnica delle Marche, Italy, Via Ranieri 65, 60100 Ancona, Italy. Tel.: +39 071 2204136; Fax: +39 071 2204123; E-mail: j.m.alvarez@univpm.it. 


\section{Introduction}

The importance of diet in the prevention of several chronic diseases has been widely recognized. In particular, the intake of fruit and vegetables has been correlated with a high intake of antioxidant and bioactive compounds that play a crucial role in the prevention of cardiovascular and neurodegenerative diseases [1-4], cancer [5-7], obesity [8], diabetes [9] and infections [10].

In the last years, an increasing interest is rising around berries, and in particular for the strawberry (Fragaria $\mathrm{x}$ ananassa Duch), because of the nutritional quality and the several bioactive compounds that it contains. Compared to other non-berry fruits previously used for human studies [11], strawberry is a relevant source of folate [12,13], is rich in vitamin $\mathrm{C}$ and contains several phytochemicals, in particular phenolic compounds that can strongly influence the nutritional and organoleptic qualities of this fruit [14-18]. The most represented polyphenols in strawberry are anthocyanins (in particular pelargonidin and cyanidin), but the anthocyanin profile can change among cultivars [19-21], depending on the genetic background [22-24], the degree of ripeness, the postharvest storage of the fruits, and the climatic factors. Another interesting group of polyphenols, less present than antocyanins, are flavonols (in particular quercetin and kaempferol derivatives) [25]. All this antioxidant compounds present in the strawberry have demonstrated positive effects on the antioxidant status of the individuals as a consequence of their properties, as reported by several studies [26-29]. Significant increase in the antioxidant status of plasma after an acute consumption of strawberry in healthy subjects has been reported, depending on the concentration of bioactive compounds in the strawberry: the upper is the antioxidant compounds content in the strawberry cultivar (in particular ascorbate), the higher is the positive effect that the acute consumption of the strawberries have on the antioxidant status of plasma [26] or on the resistance of erythrocytes to haemolysis [27] immediately after the intake; furthermore, the consumption of both fresh or stored strawberry can improve the antioxidant status of plasma in healthy subjects immediately after an acute consumption with respect to the baseline, even if the bioavailability of antioxidant compounds can be affected positively or not by the storage, that can results in a degradation of cell structures and in an impairment of the extractability of several compounds [28]. The effect of strawberry intake, however, may go further beyond the direct antioxidant effect. Recent data from in vitro experiments revealed that the antioxidant properties of strawberry flavonoids could lie in their localization in lipoprotein domains and cell membranes, which generally serve as targets for lipid peroxidation, suggesting a protective interaction of flavonoids with lipid bilayers [13].

The aim of this work was to conduct an in vivo study on healthy volunteers with a controlled diet, detecting the effect of a two-week acute consumption of strawberry cultivar "Alba" on the oxidative status in healthy subjects.

\section{Materials and methods}

\subsection{Strawberry selection and hydrophilic extraction}

Ripe strawberry fruits from Alba cultivar were obtained from the experimental field for genetic improvement of the Azienda Agraria Didattico Sperimentale "P. Rosati” (Università Politecnica delle Marche, Ancona, Italy). Within 2 hours after harvest, whole fruits were stored at $-20^{\circ} \mathrm{C}$ for further analysis.

Compounds extraction was carried out via homogenization or via sonication as previously described [14], depending on the analysis to perform. For spectrophotometric assays, the extraction was conducted via homogenization. Frozen strawberries were partially thawed and $10 \mathrm{~g}$ of fruit were added to $100 \mathrm{ml}$ of extraction solution (methanol/MilliQ water/concentrated formic acid: 80/20/0.1 v/v). Then, this solution was homogenized with an Ultraturrax T25 (Janke \& Kunkel, IKA Labortechnik) homogenizer at medium-high speed for 2 minutes. After that, the extraction was optimized by stirring the suspension for 2 hours in the dark at $4^{\circ} \mathrm{C}$. The mixture was then centrifuged at $3500 \mathrm{rpm}$ for $15 \mathrm{~min}$, and supernatant was filtered through a $0.45 \mu \mathrm{m}$ Minisart filter (PBI International) and stored in dark bottles at $-20^{\circ} \mathrm{C}$ until analysis.

For vitamin $\mathrm{C}$ analysis, fruits stored at $-80^{\circ} \mathrm{C}$ were snap-frozen in liquid nitrogen, and grounded to a fine powder using a precooled coffee grinder (IKA A11 basic). Immediately before analysis, $0.5 \mathrm{~g}$ of this powder was added to $2 \mathrm{ml}$ of extraction solution, which in the quantification of ascorbic acid consisted of $2 \mathrm{~mL}$ of ice cold water with $5 \%$ metaphosphoric acid and $1 \mathrm{mM}$ DTPA. This mixture was stirred and then sonicated at $4^{\circ} \mathrm{C}$ in the dark for 15 minutes. 
After that, the mixture was centrifuged at $2500 \mathrm{rpm}$ for 10 minutes at $4^{\circ} \mathrm{C}$ and surnatant was filtered through a $0.2 \mu \mathrm{m}$ filter PTFE and immediately analyzed.

\subsection{Determination of total antioxidant capacity (TAC) of strawberry fruits}

For the TAC determination of the hydrophilic extract, two different methodologies were used: TEAC (Trolox Equivalent Antioxidant Capacity) and FRAP (Ferric Reducing Antioxidant Power) assays.

\subsubsection{TEAC assay (FIA-ABTS decolorization assay)}

The TEAC assay was carried out using a combination of a flow injection analysis (FIA) system [30].

This method, also called FIA-ABTS decolorization assay, is based on the ability of antioxidant compounds to inactivate the 2,2'-azino-bis (3-ethylbenzothiazoline-6-sulphonic acid) or ABTS, reducing its radical ABTS ${ }^{+}$form that has the maximum absorption in the visible light, to a colorless neutral form. When biological or chemical samples containing antioxidant compounds are added to the $\mathrm{ABTS}^{+}$solution, they react neutralizing the ABTS radical and a decolorization of the solution is evident. For obtaining the $\mathrm{ABTS}^{+}$solution, an aqueous solution of ABTS $7 \mathrm{mM}$ reacted with a potassium persulphate solution $2.45 \mathrm{mM}$ and was incubated for 12 hours in the dark before use. If maintained in the dark at $25^{\circ} \mathrm{C}$, this $\mathrm{ABTS}^{+}$solution remains stable for 2 days.

The appropriated diluted strawberry extracts were injected into a serpentine-knotted reaction coil and allowed to react with the $\mathrm{ABTS}^{+}$working solution pumped into the coil at a flow rate of $1.2 \mathrm{~mL} / \mathrm{min}$. The extent of decolorization, expressed as percentage of inhibition of absorbance, was then plotted as a function of concentrations of the antioxidants in the sample and was measured through the area of a negative decolorization peak revealed by the detector. TEAC results are expressed as micromoles of Trolox equivalents per gram of FW (fresh weight) of strawberry ( $\mu$ moles $\mathrm{TE} / \mathrm{g} \mathrm{FW}$ ). Data are reported as mean value $\pm \mathrm{SD}$ (standard deviation) of four measurements.

\subsubsection{FRAP assay}

The FRAP assay was carried out as proposed by the protocol of the Scottish Crop Research Institute [31] revisited by Benzie and Strain [32]. The antioxidant capacity of the samples was determined in this assay by their ability to reduce the ferric to ferrous ion. The FRAP reagent solution was prepared immediately before analysis by combining 10 volumes of sodium acetate $(300 \mathrm{mM}, \mathrm{pH} 3.6)$ with a volume of TPTZ (2,4,6-tripyridyl-s-trizine, $10 \mathrm{mM}$ in $\mathrm{HCl}$ $40 \mathrm{mM}$ ) and a volume of ferric chloride aqueous solution $(20 \mathrm{mM})$. Trolox (an analogue of vitamin E) serial dilutions were used for calibration. The reagent mixture was prepared adding $100 \mu \mathrm{l}$ of sample (MilliQ water for the blank, Trolox standard dilutions for the calibration or strawberry hydrophilic extract diluted 10 times in water) to $900 \mu l$ of FRAP reagent solution. This mixture was rapidly stirred for 15 seconds and after 4 minutes was read at $593 \mathrm{~nm}$ in a Beckman spectrophotometer DU644 model. Results are expressed as $\mu \mathrm{mol}$ of Trolox Equivalents per 100 grams of FW of strawberry. Data are reported as mean value \pm SD of four measurements.

\subsection{HPLC determination of strawberry vitamin C content}

Vitamin C content was measured as previously described by our group [25]. Strawberry extracts were injected in a Waters 600 HPLC system controller immediately after the hydrophilic extraction (via sonication). The sample was injected in a YMC Pack Pro $150 \times 4.6 \mathrm{~mm}$ column (incubated at $30^{\circ} \mathrm{C}$ ) with an isocratic eluting solution of $50 \mathrm{mM}$ potassium phosphate $\left(\mathrm{KH}_{2} \mathrm{PO}_{4}\right)$ in MilliQ water $\mathrm{pH} 3.2$ (adjusted with phosphoric acid) for 10 minutes. Vitamin C eluting passed on a Waters 996 Photodiode array (PDA) detector set at absorbances of 262 and 244 nm; quantification of the vitamin $\mathrm{C}$ content was carried out through a calibration curve prepared by running standard concentrations of vitamin $\mathrm{C}$ similarly prepared with respect to the extracts and measured in duplicate at the beginning and at the end of the analysis. Results are expressed as milligrams of vitamin C per gram of FW (mean value of three replicates $\pm \mathrm{SD}$ ).

\subsection{Determination of total phenolic content}

The total phenolic content of the hydrophilic extracts was determined using the Folin-Ciocalteu colorimetric method, as modified by Slinkard and Singleton [33], using a calibration curve with gallic acid as the substance for the 
quantification. A standard solution of gallic acid (100 $\mu \mathrm{l})$ was added to $500 \mu \mathrm{l}$ of Folin-Ciocalteu reagent, previously diluted $1: 10$ in water and stored in the dark at $4{ }^{\circ} \mathrm{C}$. This mixture was stored for 10 minutes at room temperature, then $400 \mu \mathrm{l}$ of sodium carbonate $\left(\mathrm{Na}_{2} \mathrm{CO}_{3}\right) 0.7 \mathrm{M}$ were added and vortexed well. Then this mixture was stored for 2 hours in the dark at room temperature and the absorbance was read at $760 \mathrm{~nm}$, against the blank (consisting of distilled water instead of sample or standard). Results are expressed as milligrams of gallic acid equivalents per gram of fresh weight of strawberry (mean of four replicates) \pm SD.

\subsection{Determination of total flavonoid content}

Total flavonoid content was determined by using a colorimetric method previously described by Jia and coworkers [34] and Dewanto and co-workers [35]. Briefly, $250 \mu$ l of blank (water) or strawberry hydrophylic extract or standard solution of (+)-catechin were added to $1.25 \mathrm{ml}$ of MilliQ water in a test tube, and then $75 \mu \mathrm{l}$ of a $5 \%$ sodium nitrate solution $\left(\mathrm{NaNO}_{2}\right)$ were added. After 6 minutes of incubation, $150 \mu \mathrm{l}$ of an aluminum chloride hexahydrate $10 \%$ solution $\left(\mathrm{AlCl}_{3} * 6 \mathrm{H}_{2} \mathrm{O}\right)$ were added to the mixture. After 5 minutes of incubation, $500 \mu \mathrm{l}$ of sodium hydroxide $(\mathrm{NaOH}) 1 \mathrm{M}$ were added, the final volume was lowered to $2.5 \mathrm{ml}$ with MilliQ water and well-stirred, and the absorbance was immediately read at $510 \mathrm{~nm}$ against blank (consisting of distilled water instead of sample or standard). The results are expressed as milligrams of catechin equivalents per gram of fresh weight of strawberries $(\mathrm{mg} \mathrm{CEq} / \mathrm{g} \mathrm{FW})$ as mean value of four measurements $\pm \mathrm{SD}$.

\subsection{Determination of total anthocyanin content}

The total anthocyanin content of the hydroalcoholic strawberry extracts was determined using a modified $\mathrm{pH}$ differential method previously described [36], with some modifications. Briefly, two buffer solutions were prepared: the first with potassium chloride $(\mathrm{KCl}) 0.025 \mathrm{M}$, obtaining a $\mathrm{pH} 1$ buffer; the second with sodium acetate $\left(\mathrm{CH}_{3} \mathrm{CO}_{2} \mathrm{Na}\right)$ $0,4 \mathrm{M}$ obtaining a $4.5 \mathrm{pH}$ buffer. The stock solution for the standards consisted of a $0,46 \mathrm{mM}$ solution of pelargonidin3-glucoside (Pg-3-gluc) in $10 \mathrm{ml}$ of methanol/water $80: 20$, adjusted to $\mathrm{pH} 4$. After that, two dilutions of the strawberry extracts with the buffer solutions were prepared: the first reacted with $\mathrm{pH} 1$ buffer $(1: 10 \mathrm{v} / \mathrm{v})$, and the second reacted with $\mathrm{pH} 4.5$ buffer $(1: 10 \mathrm{v} / \mathrm{v})$. All these mixtures were incubated in the dark at room temperature for 15 minutes and then were read in a spectrophotometer at $500 \mathrm{~nm}$ (for $\mathrm{pH} 1$ mixtures) and at $700 \mathrm{~nm}$ (for $\mathrm{pH} 4.5$ mixtures) against blank (MilliQ water). Absorbance readings were converted to quantifications through a calibration curve obtained by known concentration of Pg-3-gluc standards. Results are expressed as milligrams of Pg-3-gluc equivalents per gram of fresh weight of strawberry (mg Pg-3-glc Eq/g FW) as mean value of four measurements \pm SD.

\subsection{Subjects}

Twenty-three healthy volunteers (11 men and 12 women, with a mean age of $27 \pm 3$ years and a mean BMI of $22 \pm 3 \mathrm{~kg} / \mathrm{m}^{2}$ ) were included in the study. The study was performed in accordance with the principles of the Declaration of Helsinki as revised in 2000, the protocol was approved by the Medicine School of Università Politecnica delle Marche Ethical Committee and informed written consent was obtained from each participant. The main exclusion criteria were cases of history of allergy to strawberries or other berries, the diagnosis of any chronic disease which could depends on the oxidative stress, and the presence of current symptoms of any acute illness. Smokers, minors and subjects taking dietary supplements or medications were also excluded from the test. All participants were in good health, as confirmed by the results from chemical-clinical laboratory routine tests (data not shown) performed at the laboratory analysis of INRCA (Ancona, Italy). The experimental design was carefully explained to the volunteers prior to the test.

\subsection{Study design}

The subjects were asked to abstain from eating fruits, vegetables and their juices, wine, tea or coffee for 12 hours before the test to partially standardize the baseline point, and to maintain the usual intake of dietary antioxidant compounds during the days before the experiment. Moreover, the volunteers were asked not to change their typical 
diet and to compile a detailed diary on their daily diet in the pre-study period until the beginning of the study, in order to ensure not to make changes in the eating habits, and to decrease the intake of polyphenols-rich foods during the dinner prior to every blood collection.

The first blood collection was made before the beginning of the study to take the baseline values. Then, the subjects were asked to eat 500 grams of Alba strawberries/die for 15 consecutive days between meals, in order to avoid a possible lower absorption of phytochemicals. The second blood collection was made after the conclusion of the study, at the day 15. The third and last blood samples were collected after a washout period of 15 days, in which volunteers were asked not to eat strawberries in order to cancel every possible effect of this fruit.

Blood samples were immediately collected in test-tubes containing heparin (BD Vacutainer, Plymouth, UK). Heparinized plasma was isolated after whole-blood centrifugation at $2800 \mathrm{rpm}$ for 20 minutes at $15^{\circ} \mathrm{C}$ in a multispeed refrigerated centrifuge (ALC technology, Model PK $121 \mathrm{R}$ ) and stored at $-80^{\circ} \mathrm{C}$ in cryovials until analysis.

\subsection{Plasma total antioxidant capacity $(T A C)$}

The TEAC assay was performed as previously described for strawberry fruits. The undiluted plasma samples ( $5 \mu 1)$ were injected into a serpentine-knotted reaction coil and allowed to react with $\mathrm{ABTS}^{+}$working solution pumped into the coil at a flow rate of $1.2 \mathrm{ml} / \mathrm{min}$. The extent of decolorization was expressed as percentage of absorbance inhibition, and then was graphically reported as a function of the antioxidants' concentrations in the plasma samples. Each sample was analyzed in four replicates and TEAC results are expressed as plasmatic millimolar concentration (mM) of Trolox Equivalents.

The FRAP assay was carried out as similarly described for strawberry fruits, with minor modifications. Before adding FRAP reagent, plasma samples were thawed and 5-fold diluted in MilliQ water. Trolox aqueous dilutions were used for calibration. Each sample was analyzed in four replicates and results are expressed as micromolar plasmatic concentration $(\mu \mathrm{M})$ of Trolox equivalents.

The BAP (Biological Antioxidant Potential) test is a photometric decolorization assay executable on plasma samples to determine the amount of antioxidant compounds/activity taken as the complex of agents able to reduce the iron from ferric into its ferrous form. This test was carried out diluting a small amount of plasma in a colored solution of thiocyanate and ferric chloride prepared immediately before analysis. The addition of plasma sample to the solution caused a decolorization and its extent was a function of the biological antioxidant potential, expressed as $\mu$ moles of reduced iron per liter of examined plasma at a wavelength of $505 \mathrm{~nm}$ and at $37^{\circ} \mathrm{C}$ temperature; the blank was adjusted in the spectrophotometer (manual or automatic) with the colored solution without plasma. The text must be performed on fasting patients or after a reasonable interval from an abundant meal or a strong intake of antioxidants.

Plasmatic thiolic groups (SH) were determined using a commercial kit (Diacron s.r.l., Grosseto, Italy). The method is based on the ability of -SH groups of the plasmatic components to form a colored complex when they react with 5,5'-dithiobis-2-nitrobenzoic acid (DTNB) determinable with a spectrophotometer at $405 \mathrm{~nm}$, as described by Ellman [37] and modified by Carratelli and co-workers [38]. Thiolic titration of the samples are expressed as $\mu$ moles of $-\mathrm{SH} /$ liter of sample and the amount of thiolic groups in the samples are directly correlated with the intensity of the color detected by the spectrophotometer.

\subsection{Proteins' carbonyl residues}

To carry out this test, the protein carbonyl kit (Cayman Chemical) was used. Briefly, $200 \mu$ l of plasma sample were transferred in 2 tubes: one was the sample, and one the control. Then $800 \mu \mathrm{l}$ of DNPH were added to the sample and $800 \mu \mathrm{l}$ of $\mathrm{HCl} 2.5 \mathrm{M}$ to the control and both tubes were incubated for 1 hour in the dark at room temperature, mixing the tubes every 15 minutes. After the incubation, $1 \mathrm{ml}$ of TCA $20 \%$ was added in both tubes and after stirring, the tubes were placed on ice for 5 minutes. Then the tubes were centrifuged at $10000 \mathrm{rpm}$ for 10 minutes at $4^{\circ} \mathrm{C}$, the surnatant was discarded and the pellet resuspended in $1 \mathrm{ml}$ of TCA 10\%. The tubes were placed on ice for 5 minutes and then centrifuged at $10000 \mathrm{rpm}$ for 10 minutes at $4{ }^{\circ} \mathrm{C}$. The surnatant was discarded, the pellet resuspended with a spatula in $1 \mathrm{ml}$ of ethanol/ethyl acetate (1/1), well mixed and the tubes were centrifuged at $10000 \mathrm{rpm}$ for 10 minutes at $4{ }^{\circ} \mathrm{C}$ (this step was repeated 2 times). The surnatant was discarded for the last time and the pellet resuspended 
in $500 \mu \mathrm{l}$ of guanidine hydrochloride. After stirring, the tubes were centrifuged for the last time at $10000 \mathrm{rpm}$ for 10 minutes at $4{ }^{\circ} \mathrm{C}$; then, $220 \mu \mathrm{l}$ of each sample surnatant were transferred in 2 microplate cells and $220 \mu \mathrm{l}$ of each control surnatant were transferred in 2 other microplate cells. Finally, the absorbance was read at $360-385 \mathrm{~nm}$ in a microplate reader. Final results are expressed as nmol of carbonyl residues/ml of plasma (means $\pm \mathrm{SD}$ ).

\subsection{1. d-ROMS test}

The d-ROMS test (derivatives of Reactive Oxidative Metabolites test) indicates the level of hydroperoxides circulating in the plasma. According to the kit's instructions (Diacron s.r.l., Grosseto, Italy), 3 solutions were prepared: the blank, the sample (serum or heparinized plasma) and the calibrating solution (lyophilized human matrix serum at known concentration). These solutions were incubated at $37^{\circ} \mathrm{C}$ for 75 minutes, then their absorbances were read at $505 \mathrm{~nm}$ or at $546 \mathrm{~nm}$ in a spectrophotometer. Values are expressed as U CARR (1 U CARR is equivalent to $0.08 \mathrm{mg}$ $\mathrm{H}_{2} \mathrm{O}_{2} / \mathrm{dl}$ ) and means $\pm \mathrm{SD}$ are reported.

\subsection{Statistical analysis}

Statistical analyses were performed using STATISTICA software. Data were subjected to analysis of variance, and significant differences were calculated according to Fisher test. Data are reported as mean \pm standard deviation (SD). Differences at $p<0.05$ are considered to be statistically significant.

\section{Results and discussion}

Strawberry fruits were selected in this study because of their high content in antioxidant compounds, like ascorbic acid, anthocyanins and fenolic compounds [13-21,39-42].

Table 1 shows the micronutrient and phytochemical composition of the strawberries consumed by the subjects in this study, expressed as values per gram of fresh strawberry. The results of the TEAC and the FRAP assays are closely similar to values previously obtained by our research group $[25,26]$ and confirm the high TAC of this fruit, with the FRAP value slightly lower than the TEAC value. Furthermore, the daily intake of 500 grams of strawberry in this study provides $\sim 175$ grams of vitamin $C$, that correspond to the $\sim 220 \%$ of the European RDA of vitamin $C$ (80 grams). This finding is even more important when considering that vitamin $\mathrm{C}$ provides more than $30 \%$ of the TAC of strawberry extracts [25]. The total anthocyanins content is very similar to the values previously detected, whereas the total flavonoid content is slightly lower than the values previously registered by our work group [25, 26], but differences are negligible.

In the last decades, an increased attention has been paid to the antioxidant capacity of fruit as an eligible parameter of quality. This parameter is closely linked to the presence of efficient compounds, e.g. vitamin $\mathrm{C}$ and phenolic compounds, which counteract the action of free radicals. For example, highly reactive species such as polyphenols act in plants as antioxidant compounds that protect against several sources of damage (UV, pathogens, etc.) [43].

Table 1

Characterization of strawberry extract

\begin{tabular}{lr}
\hline Type of analysis & Average value \\
\hline FRAP $(\mu \mathrm{mol} \mathrm{TE} / \mathrm{g} \mathrm{FW})$ & $8.71 \pm 0.12$ \\
TEAC $(\mu \mathrm{mol} \mathrm{TE} / \mathrm{g} \mathrm{FW})$ & $13.25 \pm 0.75$ \\
Total flavonoid contents (mg CE/g FW) & $0.216 \pm 0.03$ \\
Total anthocyanin contents (mg Pg-3-glu/g FW) & $0.49 \pm 0.14$ \\
Total phenolic contents (mg GAE/g FW) & $2.87 \pm 0.01$ \\
Total vitamin C contents (mg/g FW) & $0.35 \pm 0.02$ \\
\hline
\end{tabular}

Contents of different compounds in the strawberry extract of Alba cultivar; values are expressed as means $\pm \mathrm{SD}$. 


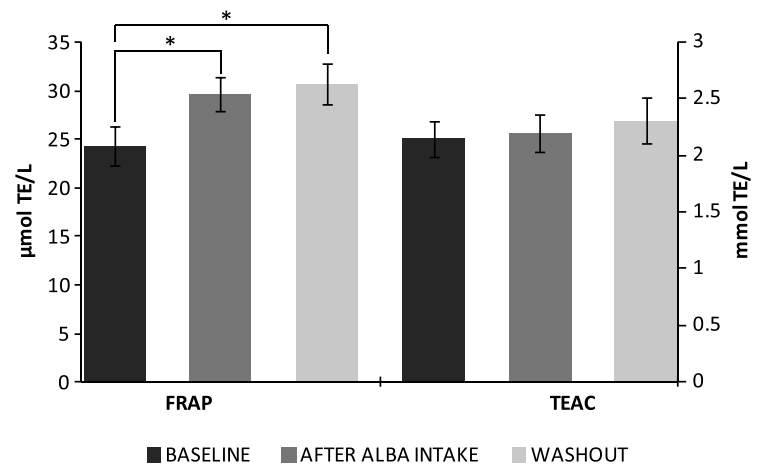

Fig. 1. Total antioxidant capacity of plasma at the baseline, following acute intake of strawberry and following a washout period of 15 days, when measured by FRAP (left side of the figure) and TEAC (right side of the picture) assays. Data are presented as mean values \pm SD. *Significant increase of $\operatorname{FRAP}(p<0.05)$.

Therefore, an important role of this compounds in controlling oxidative reaction also in humans was suggested, as well as their anti-carcinogenic and anti-atherogenic activity by direct, indirect and mediated effects [44-47].

The TAC of plasma samples was estimated from their capacity to quench $\mathrm{ABTS}^{+}$, reducing the radical to the colorless neutral form, using the TEAC assay, and by evaluating the plasma ability to reduce ferric iron by the FRAP assay. In addition, the plasma TAC was evaluated with the BAP test and the SHp test, that provide an estimate of the oxidative stress evaluating the quantity of thiolic groups present in the plasma sample. Figure 1 shows the TEAC and FRAP values of plasma at the baseline, after strawberry consumption and after a washout period of 15 days. Observing the figure, a statistically significant improvement in the plasma antioxidant capacity is evident when the FRAP test is considered (left side of the graph). In particular, after the strawberry intake, the antioxidant capacity of plasma increases from 24.25 to $29.69 \mu \mathrm{mol} \mathrm{TE} / \mathrm{L}(+22.43 \%, p<0.05)$ in respect to the baseline, and this trend is confirmed also after 15 days of washout (increase from 24.25 to $30.77 \mu \mathrm{mol}$ TE/L, $+26.89 \%$ in respect to baseline, $p<0.05)$. In contrast, significant differences in TEAC values were not found, as previously described by our group $[26,27]$. The lack of correlation between the two methods has been previously detected [48] and it depends on the different technologies and specificities of the two methods, in particular the absence of sensitivity of FRAP for SH groups-containing antioxidants, that lead to different responses to the antioxidant compounds present in plasma. So plasma proteins have a smaller influence on the FRAP data, while they make a greater relative contribution to the TEAC values [32]. The absence of any evident changes in the TEAC values after strawberry consumption could be explained by the masking effects of SH groups-containing plasma antioxidants, with respect to the finer variation of less representative compounds.

The normal values of BAP test range from 2200 to $4000 \mu$ moles/L. Anyhow, a reduction of this values under the normality range is directly correlated with a reduced efficiency of plasmatic antioxidant barrier. In this case, this condition is verified at the baseline, where values are lower than the normality $(1568.4 \mu$ moles/L). However, TAC values measured through BAP test increased significantly after Alba intake $(2509.4 \mu$ moles/L, $+60.00 \%, p<0.05)$ and continue to increase also after the washout period $(2772.3 \mu$ moles $/ \mathrm{L},+76.76 \%$ respect to the baseline,$p<0.05)$ (Fig. 2). For the SHp test, the normality range is $450-650 \mu$ moles/L and a reduction of this value under the threshold of normality indicates a reduced efficiency in the thiolic antioxidant barrier. In this study, SHp test mean values are in the normality range at the baseline $(698 \mu$ moles/L) and increased slightly after Alba intake $(724 \mu$ moles/L, $+3.72 \%)$ and after the washout period $(735 \mu$ moles $/ \mathrm{L},+5.30 \%$ respect to the baseline $)$, even if variations are not statistically significant. The plasma TAC evaluation in this study demonstrates that an acute consumption of strawberry for a period of two weeks improves in a statistically significant manner this parameter, as demonstrated by the FRAP and the BAP test. It's interesting to underline that the positive effect of strawberry consumption on the antioxidant status of plasma is detectable also after the washout period of 15 days.

The oxidative stress, however, may result in proteins' carbonyl residues formation through several mechanisms like metal-catalyzed oxidation and fragmentation, and the measurement of carbonyl residues has became a common 


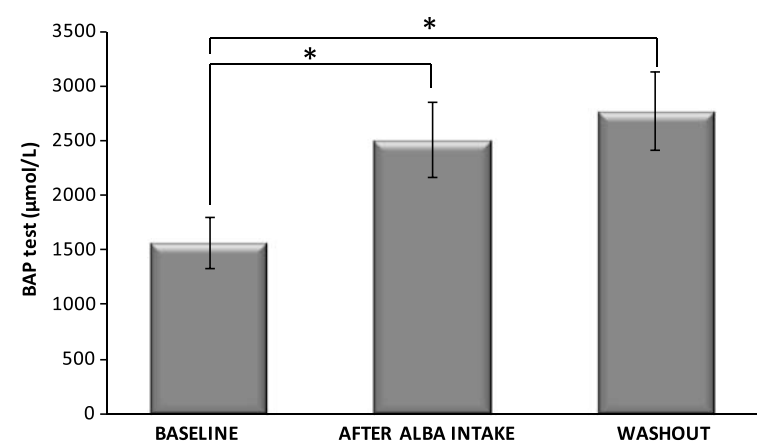

Fig. 2. BAP test values of plasma at the baseline, following acute intake of strawberry and following a washout period of 15 days. Data are presented as mean values $\pm \mathrm{SD}$. *Significant increase of $\mathrm{BAP}(p<0.05)$.

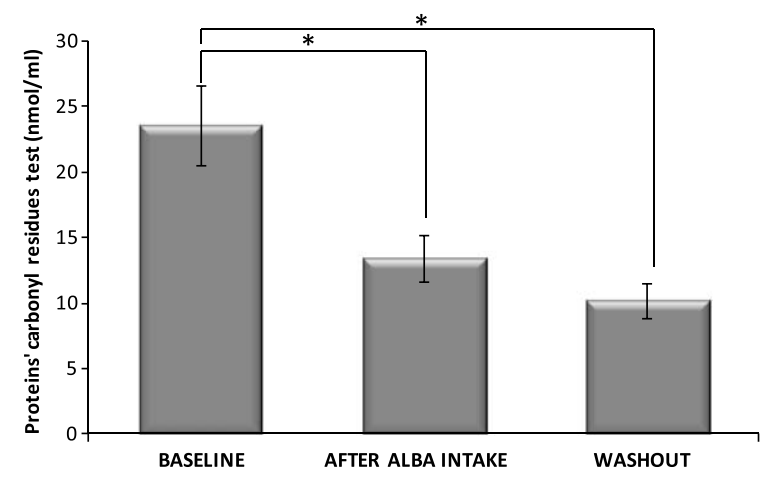

Fig. 3. Proteins' carbonyl residues test values of plasma at the baseline, following acute intake of strawberry and following a washout period of 15 days. Data are presented as mean values \pm SD. *Significant decrease of proteins' carbonyl residues $(p<0.05)$.

indicator of the oxidative damage. In this study, the proteins' carbonyl residues test was evaluated at the baseline, immediately after the strawberry supplementation and after 15 days of washout. As Fig. 3 shows, proteins' carbonyl residues values decrease significantly after Alba intake in respect to the baseline (statistically significant reduction from 23.58 to $13.43 \mathrm{nmol} / \mathrm{ml},-43.05 \%, p<0.05)$. Interesting is the fact that also after 15 days of washout, the value of proteins' carbonyl residues continue to decrease in respect to the baseline (from 23.58 to $10.21 \mathrm{nmol} / \mathrm{ml},-56.71 \%$, $p<0.05$ ). This evidence seems to demonstrate that the acute strawberry consumption of 15 days may have a protective effect against the oxidative stress that results in a proteins' carbonyl residues reduction. This positive effect remains active also after 15 days of suspension of strawberry consumption. This result confirms the healthy effect of berry fruit on the oxidative status of plasma detected in a previous study [49], in which a cranberry juice intervention of 8 weeks caused a significant decrease in both ox-LDL and MDA versus placebo treatment, two indicators of the oxidative status of plasma proteins.

Another parameter of oxidative damage taken in account in this study was the d-ROMs test, which indicates the level of hydroperoxides circulating in the plasma, as stated before: the higher is the value registered, the higher is the oxidative damage resulting in the individual. The results show that, compared to the initial value of the baseline (312.26 U CARR), the quantity of d-ROMs measured by the test decreases significantly after the period of Alba consumption (239.56 U CARR, $-23.28 \%, p<0.05)$. Furthermore, after two weeks of washout, the value remains similar to the value registered after the strawberry intake (227.96 U CARR, $-27 \%$ in respect to the baseline, $p<0.05$ ), and this result seems to indicate that the protective effect of strawberry consumption detected immediately after 15 days of Alba intake on the level of hydroperoxides circulating in the plasma, remains active until 2 weeks after the end of strawberry supplementation (Fig. 4). The normality range for the d-ROM test is 250-300 U CARR, and an 


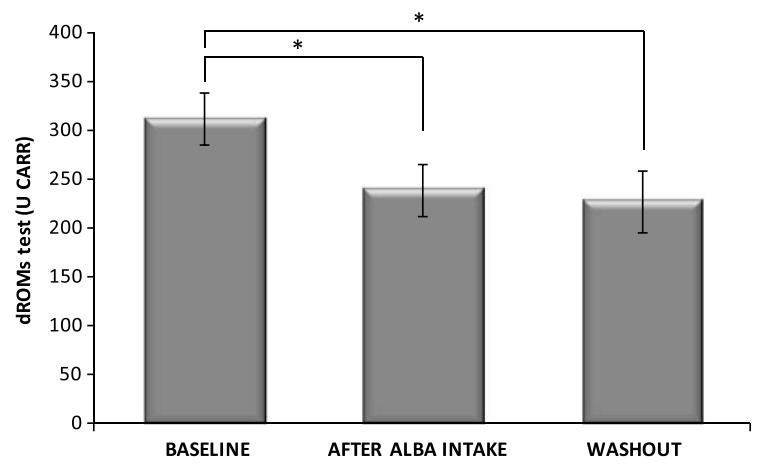

Fig. 4. d-ROMs test values of plasma at the baseline, following acute intake of strawberry and following a washout period of 15 days. Data are presented as mean values \pm SD. *Significant decrease of d-ROMs $(p<0.05)$.

upper value indicates a condition of oxidative stress. As the results show, the baseline value is slightly over this range, and the acute strawberry consumption is capable to reduce this parameter in the normality range, and this effect is still active also after the washout period.

As indicated by several studies on a large number of dietary plants, strawberries are among the richest fruits in antioxidant compounds. Furthermore, strawberries are the most consumed berries both in fresh and processed forms, and the potential antioxidant and biological efficacy of their compounds is currently receiving an increasing attention.

This study confirms the nutritional quality of Alba strawberry cultivar detected in other previously works [25, 26] and the obtained results seems to demonstrate that the antioxidant capacity of plasma is increased in 23 healthy volunteers undergone to a two weeks period of acute strawberry consumption, and therefore indicators of oxidative stress, like proteins' carbonyl residues and d-ROMs test, show lower values after the strawberry consumption than the baseline, indicating a positive effect of strawberries in reducing the oxidative damage of plasma proteins. Interestingly, after the washout period the positive effect of strawberry consumption is increased, and this finding allows supposing that there may be a delayed effect of strawberry compounds on the antioxidant status of the plasma.

\section{References}

[1] Johnsen SP, Overvad K, Stripp C, Tionneland A, Husted SE, Sorensen HT. Intake of fruit and vegetables and the risk of ischaemic stroke in a cohort of Danish men and women. Am J Clin Nutr 2003;78:57-64.

[2] Heinonen IM, Meyer AS, Frankel EN. Antioxidant activity of berry phenolics on human low-density lipoprotein and liposome oxidation. J Agric Food Chem 1998;46:4107-12.

[3] De Ruvo C, Amodio R, Algeri S, Martelli N, Intilangelo A, D’Ancona GM, Esposito E. Nutritional antioxidants as antidegenerative agents. Int J Dev Neurosci 2000;18:359-66.

[4] Vauzour D, Vafeiadou K, Rendeiro C, Corona G, Spencer JPE. The inhibitory effects of berry-derived flavonoids against neurodegenerative processes. J Berry Res 2010;1:45-52.

[5] Etminan M, Takkouche B, Caamano-Isorna F. The role of tomato products and lycopene in the prevention of prostate cancer: A meta-analysis of observational studies. Cancer Epidemiol Biomarkers Prev 2004;13:340-45.

[6] Smith-Warner SA, Spiegelman D, Yaun SS, Albanes D, Beeson WL, van den Brandt PA, et al. Fruits, vegetables and lung cancer: A pooled analysis of cohort studies. Int J Cancer 2003;107:1001-11.

[7] Yi-Fang C, Jie S, Xianzhong W, Rui HL. Antioxidant and antiproliferative activities of common vegetables. J Agric Food Chem 2002;50:6910-16.

[8] Papathanasopoulos A, Camilleri M. Dietary fiber supplements: Effects in obesity and metabolic syndrome and relationship to gastrointestinal functions. Gastroenterology 2010;138(1):65-72.

[9] Carter P, Gray LJ, Troughton J, Khunti K, Davies MJ. Fruit and vegetable intake and incidence of type 2 diabetes mellitus: Systematic review and meta-analysis. BMJ 2010;341:c4229.

[10] Holt EM, Steffen LM, Moran A, Basu S, Steinberger J, Ross JA, et al. Fruit and vegetable consumption and its relation to markers of inflammation and oxidative stress in adolescents. J Am Diet Assoc 2009;109(3):414-21. 
[11] Lotito SB, Frei B. The increase in human plasma antioxidant capacity after apples consumption is due to the metabolic effect of fructose on urate, not apple-derived antioxidant flavonoids. Free Radic Biol Med 2004; 37:251-58.

[12] Olsson ME, Ekvall J, Gustavsson K, Nilsson J, Pillai D, Sjoholm I, et al. Antioxidant, low molecular weight carbohydrates, and total antioxidant capacity in strawberry (Fragaria $\times$ ananassa): Effects of cultivar, ripening, and storage. J Agric Food Chem 2004;52: 2490-98.

[13] Tulipani S, Romandini S, Alvarez Suarez JM, Capocasa F, Mezzetti B, Busco F, et al. Folate content in different strawberry genotypes and folate status in healthy subjects after strawberry consumption. Biofactors 2008;34:47-55.

[14] Scalzo J, Politi A, Pellegrini N, Mezzetti B, Battino M. Plant genotype affects total antioxidant capacity and phenolic contents in fruit. Nutrition 2005;21:207-13.

[15] Proteggente AR, Pannala AS, Paganga G, Van Buren L, Wagner E, Wiseman S, et al. The antioxidant activity of regular consumed fruit and vegetables reflects their phenolic and vitamin C composition. Free Rad Res 2002;36:217-33.

[16] Deighton N, Brennan R, Finn C, Davies HV. Antioxidant properties of domesticated and wild Rubus species. J Sci Food Agric 2000;80:130713.

[17] Tulipani S, Mezzetti B, Battino M. Impact of strawberries on human health: Insight into marginally discussed bioactive compounds for the mediterranean diet. Public Health Nutr 2009;12(9A):1656-1662.

[18] Giampieri F, Tulipani S, Alvarez-Suarez JM, Quiles JL, Mezzetti B, Battino M. The strawberry: Composition, nutritional quality, and impact on human health. Nutrition 2012; 28:9-19.

[19] Määtta KR, Kamal-Eldin A, Törrönen AR. Identification and quantification of phenolic compounds in berries of Fragaria and Rubus species (family Rosaceae). J Agric Food Chem 2004; 52:6178-87.

[20] Lopes-da-Silva F, Escribano-Bailòn MT, Pérez Alonso JJ, Rivas-Gonzalo JC, Santos-Buelga C. Anthocyanin pigments in strawberry. LWT 2007;40:374-82.

[21] Alvarez-Suarez JM, Dekanski D, Ristic S, Radonjic NV, Petronijevic ND, Giampieri F, et al. Strawberry polyphenols attenuate ethanolinduced gastric lesions in rats by activation of antioxidant enzymes and attenuation of MDA increase. PLoS One 2011;6(10):e25878.

[22] Diamanti J, Capocasa F, Battino M, Mezzetti B. Evaluation of $F . \mathrm{x}$ ananassa intra-specific and inter-specific back-crosses to generate new genetic material with increased fruit nutritional quality. J Berry Res 2010;1:103-14.

[23] Battino M, Mezzetti B. Update on fruit antioxidant capacity: A key tool for Mediterranean diet. Public Health Nutr 2006;9(8A):1099-03.

[24] Diamanti J, Capocasa F, Balducci F, Battino M, Hancock J, Mezzetti B. Increasing strawberry fruit sensorial and nutritional quality using wild and cultivated germplasm. PLoS One 2010;7(10):e46470.

[25] Tulipani S, Mezzetti B, Capocasa F, Bompadre S, Beekwilder J, Ric De Vos CH, et al. Antioxidants, phenolic compounds, and nutritional quality of different strawberry genotypes. J Agric Food Chem 2008;56(3):696-704.

[26] Tulipani S, Romandini S, Busco F, Bompadre S, Mezzetti B, Battino M. Ascorbate, not urate, modulates the plasma antioxidant capacity after strawberry intake. Food Chem 2009;117:181-88.

[27] Tulipani S, Alvarez-Suarez JM, Busco F, Bompadre S, Quiles JL, Mezzetti B, Battino M. Strawberry consumption improve plasma antioxidant status and erythrocyte resistance to oxidative haemolysis in humans. Food Chem 2011; 128:180-86.

[28] Azzini E, Intorre F, Vitaglione P, Napolitano A, Foddai MS, Durazzo A, et al. Absorption of strawberry phytochemicals and antioxidant status changes in humans. J Berry Res 2010;1:81-89.

[29] Battino M, Beekwilder J, Denoyes-Rothan B, Laimer M, McDougall GJ, Mezzetti B. Bioactive compounds in berries relevant to human health. Nutr Rev 2009;67Suppl1:145-50.

[30] Bompadre S, Leone L, Politi A, Battino M. Improved FIA-ABTS method for antioxidant capacity determination in different biological samples. Free Radical Res 2004;38:831-38.

[31] Deighton N, Brennan R, Finn C, Davies HV. Antioxidant properties of domesticated and wild rubus species. J Sci Food Agric 2000;80:130713.

[32] Benzie IF, Strain JJ. Ferric reducing ability of plasma (FRAP) as a measure of antioxidant power: The FRAP assay. Anal Biochem 1996;239:70-76.

[33] Slinkard K, Singleton VL. Total phenol analysis: Automation and comparison with manual methods. Am J Enol Vitic 1977;28:49-55.

[34] Jia Z, Tang M, Wu J. The determination of flavonoid contents in mulberry and their scavenging effects on superoxides radicals. Food Chem 1998;64:555-59.

[35] Dewanto V, Wu X, Adom KK, Liu RH. Thermal processing enhances the nutritional values of tomatoes by increasing the total antioxidant activity. J Agric Food Chem 2002;50:3010-14.

[36] Giusti MM, Wrolstad RE. Characterization and measurements of anthocyanins by UV-visible spectroscopy. In Curr Prot Food Anal Chem 2001.

[37] Ellman G. Tissue sulphydryl groups. Arch Biochem Biophys 1959;32:70-77.

[38] Carratelli M, Porcaro R, Rustica M, De Simone E, Bertelli AAE, Corsi MM. Reactive oxygen metabolites (ROMs) and prooxidant status in children with Down Syndrome. Int J Clin Pharmacol Res 2001;21:79-84.

[39] Kalt W, Forney CF, Martin A, Prior RL. Antioxidant capacity, vitamin C, phenolics, and anthocyanins after fresh storage of small fruits. J Agric Food Chem 1999;47:4638-44. 
[40] Wang SY, Hsin-Shan L. Antioxidant activity in fruits and leaves of blackberry, raspberry, and strawberry varies with cultivar and developmental stage. J Agric Food Chem 2000;48:140-46.

[41] Wang SY, Zheng W, Galletta GJ. Cultural system affects fruit quality and antioxidant capacity in strawberries. J Agric Food Chem 2002;50:6534-42.

[42] Scalzo J, Mezzetti B, Battino M. Total antioxidant evaluation: Critical steps for assaying berry antioxidant features. BioFactors 2005;23:22127.

[43] Schijlen E, Ric de Vos CH, Jonker H, van den Broeck H, Molthoff J, van Tunen A, et al. Pathway engineering for healthy phytochemicals leading to the production of novel flavonoids in tomato fruit. Plant Biotechnol J 2006;4:433-44.

[44] Decker EA. The role of phenolics, conjugated linoleic acid, carnosine, and pyrroloquinoline quinone as nonessential dietary antioxidants. Nutr Rev 1995;53:49-58.

[45] Middleton E Jr, Kandaswami C. Effects of flavonoids on immune and inflammatory cell functions. Biochem Pharmacol 1992;43:1167-79.

[46] Nakayama T. Suppression of hydroperoxide-induced cytotoxicity by polyphenols. Cancer Res 1994;54:1991s-93s.

[47] Giampieri F, Alvarez-Suarez JM, Tulipani S, Gonzales-Paramas AM, Santos-Buelga C, Bompadre S, et al. Photoprotective potential of strawberry (fragaria x ananassa) extract against UV-A irradiation damage on human fibroblasts. J Agric Food Chem 2012;60:2322-27.

[48] Cao G, Prior RL. Comparison of different analytical methods for assessing total antioxidant capacity of human serum. Clin Chem 1998;44:1309-15.

[49] Basu A, Betts NM, Ortiz J, Simmons B, Wu M, Lyons TJ. Low-energy cranberry juice decreases lipid oxidation and increases plasma antioxidant capacity in women with metabolic syndrome. Nutr Res 2011;31:190-96. 